\title{
Gambaran Esofagogastroduodenoskopi Pasien Hematemesis dan atau Melena di RSUP M Djamil Padang Periode Januari 2010 - Desember 2013
}

\author{
Fadhil Alfino Azmi ${ }^{1}$, Saptino Miro ${ }^{2}$, Detty Iryani ${ }^{3}$
}

\begin{abstract}
Abstrak
Perdarahan saluran cerna bagian atas adalah kehilangan darah dalam lumen saluran cerna yang bermula dari esofagus sampai duodenum. Manifestasi kinis berupa hematemesis (muntah darah) dan atau melena (tinja hitam). Kasus ini masih banyak dilaporkan dari berbagai rumah sakit. Etiologi yang sering dilaporkan adalah varises esofagus, ulkus peptikum, gastritis erosif dan lain-lain. Tujuan penelitian ini adalah mengetahui frekuensi diagnosis esofagogastroduodenoskopi (EGD) pasien hematemesis dan atau melena di RSUP M Djamil Padang. Jenis penelitian yang digunakan adalah deskriptif retrospektif. Data diambil secara total sampling dari rekam medik pasien hematemesis dan atau melena yang dilakukan pemeriksaan EGD di Instalasi Diagnostik Terpadu (IDT) RSUP M Djamil Padang periode.Januari.2010.-.Desember.2013. Hasil penelitian menunjukkan 162 pasien kasus terbanyak adalah ulkus gaster $(27,8 \%)$. Menurut jenis kelamin, pria lebih banyak dibanding wanita yaitu pria $(64,8 \%)$ dan wanita $(35,2 \%)$ rasio $1,8: 1$. Kelompok umur terbanyak adalah $51-60$ tahun yaitu $(20,0 \%)$. Lokasi lesi yang paling banyak ditemukan adalah gaster $(48,8 \%)$.
\end{abstract}

Kata kunci: esofagogastroduodenoskopi, perdarahan saluran cerna bagian atas, hematemesis, melena

\begin{abstract}
Upper gastrointestinal bleeding is a loss of blood in lumen of the gastrointestinal tract from esophagus to duodenum. Clinical manifestations are hematemesis (vomiting of blood) and/or melena (black stools). Many cases were widely reported from various hospitals. The most common etiology that often being reported are esophageal varices, peptic ulcer, erosive gastritis, etc. The objective of this study was to determine the frequency of esophagogastroduodenoscopy(EGD) findings in patients with hematemesis and/or melena in M Djamil Hospital Padang. The design of this research was retrospective descriptive. Data was taken from the result of patient's EGD examination(medical records) that having hematemesis and/or melena in Integrated Diagnostics Installation of $M$ Djamil Hospital Padang from January 2010 to December 2013. The results showed that the highest cases of 162 patients were gastric ulcer (27.8\%). According to gender, more men cases than women cases. Men (64.8\%) and women $(35.2 \%)$ with ratio $1.8: 1$. Most cases occurred on 51-60 years old (20.0\%). Location of lesions were most commonly found in gaster (48.8\%).
\end{abstract}

Keywords: esophagogastroduodenoscopy, upper gastrointestinal bleeding, hematemesis, melena

Affiliasi penulis: 1. Pendidikan Dokter FK UNAND (Fakultas Kedokteran Universitas Andalas Padang), 2. Bagian Penyakit Dalam FK UNAND/RSUP dr. M. Djamil Padang, 3. Bagian Fisiologi FK UNAND

Korespondensi Fadhil Alfino Azmi, Email:fadhil.wcc@gmail.com, Telp: 085271169934

\section{PENDAHULUAN}

Perdarahan saluran cerna dapat berasal dari saluran cerna bagian atas(SCBA) atau saluran cerna bagian bawah(SCBB). Manifestasi klinisnya dapat sangat bervariasi mulai dari yang ringan, sampai dengan perdarahan masif dan renjatan. Perdarahan saluran cerna bagian atas adalah kehilangan darah 
dalam lumen saluran cerna mulai dari esofagus sampai dengan duodenum (dengan batas anatomik di ligamentum treitz). Perdarahan saluran cerna bagian bawah didefinisikan sebagai perdarahan yang berasal dari usus di sebelah bawah ligamentum treitz. Gejala perdarahan saluran cerna bagian atas dapat berupa hematemesis (muntah darah segar atau hitam) dan atau melena (tinja hitam dengan bau khas) atau berupa hematokezia apabila perdarahan yang terjadi dengan jumlah yang banyak (masif). Gejala perdarahan saluran cerna bagian bawah pada umumnya berupa hematokezia atau perdarahan samar saluran cerna. ${ }^{1-3}$

Alat esofagogastroduodenoskopi

(EGD) memungkinkan diagnosis yang tepat terhadap kelainan organ dalam tubuh manusia. Hal tersebut dikarenakan EGD dapat melihat langsung dengan melihat ke dalam tubuh, sehingga dapat dilihat dengan jelas setiap kelainan yang ada pada organ yang diperiksa. Oleh karena itu jelas bahwa EGD termasuk salah satu sarana penunjang diagnostik yang penting. Dengan makin berkembangnya alat tersebut ternyata tidak hanya digunakan sebagai sarana diagnostik saja, tetapi kemudian dimanfaatkan sebagai sarana untuk terapi. Sebagai sarana diagnostik seperti menentukan dengan lebih pasti/tepat kelainan radiologis yang didapatkan pada esofagus, lambung dan duodenum, selain itu juga untuk kasus sindroma dispepsia dengan usia lebih 45 tahun atau di bawah 45 tahun dengan tanda bahaya seperti muntah-muntah hebat, anemia, ikterus,penurunan berat badan, indikasi lainnya adalah riwayat pemakaian Obat Analgetik Antipiretik Inflamasi Non Steroid (OAINS) dan riwayat kanker pada keluarga serta yang sangat penting pada perdarahan SCBA. ${ }^{4,5}$

Etiologi perdarahan saluran cerna atas di Indonesia berbeda dengan yang dilaporkan kepustakaan barat. Di Indonesia sebagian besar kasus perdarahan SCBA (lebih kurang 70\%) disebabkan oleh pecahnya varises esofagus atau dampak lain dari akibat adanya hipertensi portal (adanya gastropati hipertensi portal). Sedangkan di Negara Barat sebagian besar di akibatkan tukak peptik dan gastritis erosif. Penyebab lain yang sering dilaporkan pada perdarahan SCBA adalah sindroma mallory-weiss dan keganasan SCBA. ${ }^{1,3,6}$
Perbedaan etiologi terbanyak di negara Barat dan di Indonesia ini dapat dilihat pada penelitian Hreinsson pada tahun 2012 di Islandia, dimana temuan terbanyak adalah ulkus peptikum (35,2\%) diikuti oleh sindroma Mallory-Weiss (12,2\%). Penelitian Hearnshaw pada tahun 2010 di Inggris, kasus terbanyak adalah ulkus peptikum sebanyak $36 \%$, diikuti oleh varises esofagus sebanyak $11 \%$. Di Indonesia, berdasarkan penelitian Adi pada tahun 2009 dari 1673 kasus perdarahan SCBA di SMF Penyakit Dalam RSU dr Soetomo Surabaya, penyebabnya $76,9 \%$ pecahnya varises esofagus, $19,2 \%$ gastritis erosif, 1,0\% tukak peptik, 0,6\% kanker lambung, dan 2,6\% karena sebab-sebab lain. ${ }^{7-9}$

Menurut jenis kelamin dan kelompok umur dari kasus perdarahan saluran cerna atas adalah sebagai berikut: 1) Tukak lambung lebih sering terjadi pada pria dibandingkan wanita (1,3:1). Walaupun dapat terjadi pada semua kelompok umur, tukak lambung lebih sering terjadi pada kelompok umur 55-70 tahun; 2) Pada tukak duodenum, perbandingan antara lakilaki dengan wanita (2:1). Umur terbanyak antara kelompok umur 45-65 tahun dengan kecendrungan makin tua umur, prevalensi makin meningkat; 3) Kanker gaster pada pria dua kali lebih sering daripada wanita. Kebanyakan kasus kanker lambung terjadi pada umur 50-70 tahun dan jarang di bawah umur 40 tahun. $^{10-12}$

\section{METODE}

Jenis penelitian adalah deskriptif retrospektif dengan menggunakan data sekunder dari Instalasi Diagnostik Terpadu (IDT) RSUP M Djamil Padang. Penelitian dilakukan di Instalasi Diagnostik Terpadu (IDT) RSUP M Djamil Padang pada awal bulan Maret hingga pertengahan April 2014. Populasi pada penelitian ini adalah seluruh data sekunder esofagogastroduodenoskopi dari Instalasi Diagnostik Terpadu (IDT) RSUP M Djamil Padang selama empat tahun (periode Januari 2010 - Desember 2013). Sampel pada penelitian ini diambil secara total sampling terhadap pasien dengan keluhan hematemesis dan atau melena. Data dikumpulkan dari catatan esofagogastroduodenoskopi pasien dengan keluhan hematemesis dan atau melena di Instalasi Diagnostik Terpadu (IDT) RSUP dr. M. Djamil Padang 
pada periode Januari 2010 - Desember 2013. Data yang dicatat adalah umur, jenis kelamin, diagnosis dari pemeriksaan EGD. Pengolahan data dilakukan secara manual dan kemudian disajikan dalam bentuk tabel distribusi frekuensi dan diagram pai.

HASIL

Hasil penelitian yang telah dilakukan di Instalas Diagnostik Terpadu (IDT) RSUP M Djamil Padang selama periode Januari 2010 - Desember 2013, didapatkan sebanyak 1598 pasien yang dilakukan pemeriksaan EGD. Sebanyak 176 pasien diantaranya adalah dengan hematemesis dan atau melena. Sebanyak 162 pasien dapat dijadikan sampel dan sebanyak 14 pasien tak dapat dimasukkan dalam penelitian ini disebabkan karena ketidaklengkapan data, batal karena tidak kooperatif atau keadaan umum lemah. Hasil penelitian ini dapat dilihat pada tabel-tabel berikut.

Tabel 1. Distribusi frekuensi diagnosis EGD pasien hematemesis dan atau melena

\begin{tabular}{llcc}
\hline \multirow{2}{*}{ No } & \multicolumn{2}{c}{ Diagnosis EGD } & \multicolumn{2}{c}{ Jumlah } \\
\cline { 3 - 4 } & & $\mathbf{n}$ & $\%$ \\
\hline 1 & Ulkus Gaster & 45 & 27,8 \\
2 & Pecahnya Varises Esofagus & 22 & 13,6 \\
3 & Gastritis erosif & 15 & 9,3 \\
4 & Ulkus Duodeni & 11 & 6,8 \\
5 & Tumor Gaster & 4 & 2,4 \\
6 & Tumor Esofagus & 2 & 1,2 \\
7 & Ulkus Esofagus & 1 & 0,6 \\
8 & Multi Lesi & 62 & 38,3 \\
\hline & TOTAL & 162 & 100 \\
\hline
\end{tabular}

Tabel 1 memperlihatkan diagnosis esofagogastroduoenoskopi (EGD) yang terbanyak didapatkan pada penelitian ini adalah multi lesi 62 kasus $(38,3 \%)$. Sedangkan untuk diagnosis tunggal yang terbanyak didapatkan adalah ulkus gaster sebanyak 45 kasus $(27,8 \%)$. Multi lesi adalah suatu keadaan dimana pada satu pasien dapat didapatkan dua atau lebih kelainan dari hasil pemeriksaan EGD, seperti gastritis erosif dengan ulkus gaster atau pecahnya varises esofagus, gastropati hipertensi portal dan ulkus gaster.
Tabel 2. Distribusi frekuensi diagnosis EGD pasien hematemesis dan atau melena menurut jenis kelamin

\begin{tabular}{llcccc}
\hline \multirow{2}{*}{ No } & \multirow{2}{*}{ Diagnosis EGD } & \multicolumn{2}{c}{ Pria } & \multicolumn{2}{c}{ Wanita } \\
\cline { 2 - 5 } & & $\mathbf{n}$ & $\%$ & $\mathbf{n}$ & $\%$ \\
\hline 1 & Ulkus Gaster & 27 & 60,0 & 18 & 40,0 \\
& Pecahnya & & & & \\
\multirow{2}{*}{2} & Varises & & & & \\
3 & Esofagus & 18 & 81,8 & 4 & 18,2 \\
4 & Gastritis erosif & 7 & 46,7 & 8 & 53,3 \\
5 & Ulkus Duodeni & 9 & 81,8 & 2 & 18,2 \\
6 & Tumor Gaster & 2 & 50,0 & 2 & 50,0 \\
7 & Tumor Esofagus & 0 & 0 & 2 & 100 \\
8 & Ulkus Esofagus & 0 & 0 & 1 & 100 \\
& Multi Lesi & 42 & 67,7 & 20 & 32,3 \\
\hline & TOTAL & 105 & 64,8 & 57 & 35,2 \\
\hline
\end{tabular}

Pada Tabel 2 diatas dapat dilihat bahwa pasien dengan hematemesis dan atau melena yang dilakukan esofagogastroduodenoskopi (EGD) menurut jenis kelamin di RSUP M Djamil Padang didapatkan bahwa kasus terbanyak adalah pada pria yaitu 105 kasus $(64,8 \%)$ dan pada wanita sebanyak 57 kasus $(35,2 \%)$. Pada kasus ulkus gaster, jumlah pasien pria sebanyak 27 orang $(60,0 \%)$ dan wanita 18 orang $(40,0 \%)$. Sedangkan pada pecahnya varises esofagus jumlah pasien pria 18 orang $(81,8 \%)$ dan wanita 4 orang $(18,2 \%)$.

Tabel 3. Distribusi frekuensi gambaran EGD pasien hematemesis dan atau melena menurut kelompok umur

\begin{tabular}{|c|c|c|c|c|c|c|c|c|}
\hline \multirow{3}{*}{$\begin{array}{c}\text { Diagnosis } \\
\text { EGD }\end{array}$} & \multicolumn{8}{|c|}{ Kelompok Umur } \\
\hline & $\begin{array}{c}11-20 \\
\text { th }\end{array}$ & $\begin{array}{l}21-30 \\
\text { th }\end{array}$ & $\begin{array}{c}31-40 \\
\text { th }\end{array}$ & $\begin{array}{l}41-50 \\
\text { th }\end{array}$ & $51-60$ th & $\begin{array}{l}61- \\
70 \\
\text { th }\end{array}$ & $\begin{array}{l}71- \\
80 \\
\text { th }\end{array}$ & $\begin{array}{l}81- \\
90 \text { th }\end{array}$ \\
\hline & $\%$ & $\%$ & $\%$ & $\%$ & $\%$ & $\%$ & $\%$ & $\%$ \\
\hline & 0 & 4,4 & 0 & 20,0 & 26,6 & 22,2 & 22,2 & $\overline{4,4}$ \\
\hline Ulkus Gaster & & & & & & & & \\
\hline $\begin{array}{l}\text { Pecahnya } \\
\text { Varises }\end{array}$ & 0 & 4,5 & 9,1 & 40,9 & 22,8 & 18,2 & 4,5 & 0 \\
\hline & 6,7 & 13,3 & 6,7 & 20,0 & 20,0 & 26,6 & 6,7 & 0 \\
\hline Gastritis erosif & & & & & & & & \\
\hline & 0 & 0 & 9,0 & 18,2 & 27,3 & 18,2 & 27,3 & 0 \\
\hline Ulkus Duodeni & & & & & & & & \\
\hline Tumor Gaster & & & & & & & & \\
\hline Tumor & 0 & 0 & 0 & 0 & 50,0 & 0 & 50,0 & 0 \\
\hline & 0 & 0 & 0 & 0 & 0 & 100 & 0 & 0 \\
\hline Ulkus Esofagus & & & & & & & & \\
\hline & 0 & 3,2 & 4,8 & 19,4 & 32,3 & 27,4 & 9,7 & 3,2 \\
\hline Multi Lesi & & & & & & & & \\
\hline TOTAL & 0,6 & 4,9 & 4,3 & 22,2 & 29,0 & 22,8 & 13,6 & 2,5 \\
\hline
\end{tabular}


Tabel 3 menggambarkan kelompok umur 51-60 tahun adalah kelompok umur yang terbanyak ditemukan pada hasil penelitian ini yaitu sebanyak 47 kasus $(29,0 \%)$. Berdasarkan diagnosis, untuk ulkus gaster terbanyak pada kelompok umur 51-60 tahun 12 kasus $(26,6 \%)$ dan pecahnya varises esofagus terbanyak pada kelompok umur 41-50 tahun 9 kasus $(40,9 \%)$.

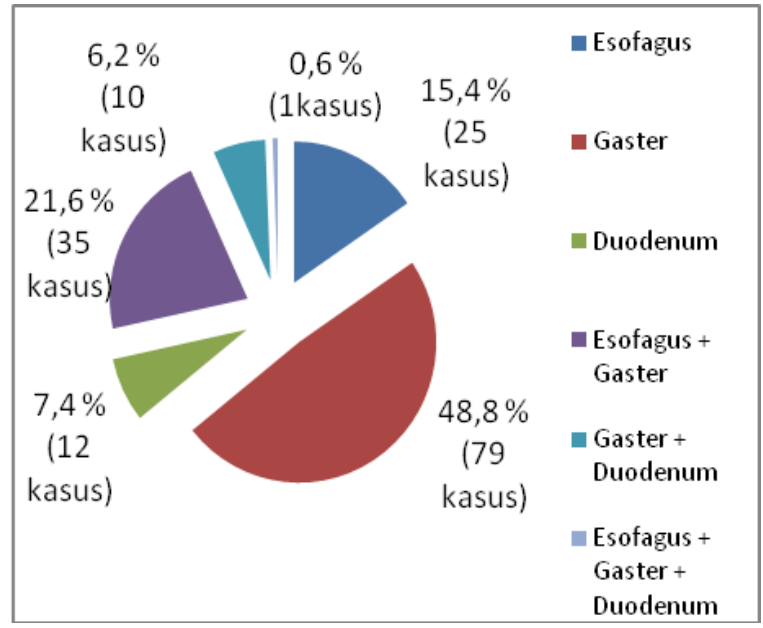

Gambar 1. Distribusi frekuensi lokasi lesi pada pasien hematemesis dan atau melena

Gambar 1 memperlihatkan bahwa lokasi lesi dari pasien hematemesis dan atau melena paling banyak ditemukan pada gaster yaitu 79 kasus (48,8\%). Lokasi ini didapatkan dari 162 pasien hematemesis dan atau melena yang dilakukan EGD.

\section{PEMBAHASAN}

Berdasarkan penelitian yang telah dilakukan di Instalasi Diagnostik Terpadu (IDT) RSUP M Djamil Padang didapatkan 162 pasien dengan hematemesis dan atau melena yang dilakukan pemeriksaan EGD mulai Januari 2010 sampai Desember 2013. Distribusi frekuensi gambaran esofagoduodenoskopi (EGD) pasien hematemesis dan atau melena menunjukkan bahwa diagnosis EGD yang terbanyak adalah ulkus gaster $(27,8 \%)$, kemudian diikuti dengan pecahnya varises esofagus $(13,6 \%)$, dan gastritis erosif $(9,6 \%)$. Pada penelitian lainnya, varises esofagus merupakan kasus terbanyak yang ditemukan. RSU dr Soetomo Surabaya kasus varises esofagus sebanyak $76,9 \%$, ${ }^{9}$ RSUP Cipto Mangunkusumo Jakarta 33,5\%, ${ }^{13}$ dan RS Lacor Uganda 40,6\%. ${ }^{14}$ Tingginya kasus ulkus gaster dan gastritis erosif di RSUP M. Djamil Padang dibandingkan dengan RSU dr. Soetomo Surabaya, RSUP Cipto Mangunkusumo Jakarta dan RS Lacor Uganda kemungkinan dapat disebabkan oleh pola makan masyarakat Padang yang cenderung makan makanan yang pedas. Hal ini sesuai dengan Hadi pada tahun 2002 bahwa salah satu penyebab ulkus gaster dan gastritis erosif adalah kebiasaan makan makanan yang pedas dan minum yang panas yang dapat merusak (harmful) pada mukosa lambung dan usus. $^{15}$

Distribusi frekuensi gambaran EGD pasien dengan hematemesis dan atau melena menurut jenis kelamin, terlihat bahwa kasus lebih banyak terjadi pada pria yaitu sebanyak 105 kasus $(64,8 \%)$ dan pada wanita sebanyak 57 kasus $(35,2 \%)$ dengan rasio 1,8:1. Hasil yang hampir sama ditemukan pada penelitian Alema et al pada tahun 2012, dimana pasien dengan perdarahan saluran cerna bagian atas yang dilakukan pemeriksaan EGD didapatkan pria 113 kasus $(50,4 \%)$ dan wanita 111 kasus $(49,6 \%)$ dengan rasio $1: 1 .^{14}$

Pada kasus pecahnya varises esofagus, jumlah kasus pria adalah 18 kasus (81,8\%) dan wanita 4 kasus $(18,2 \%)$ dengan rasio $4,5: 1$. Hasil ini sesuai dengan yang dilaporkan Hadi pada tahun 2002 dan Alema pada tahun 2012, dimana pria juga lebih banyak wanita dengan rasio 1,6:1.

Pada penelitian ini jenis kelamin pria lebih banyak ditemukan dibandingkan wanita. Hal ini dapat disebabkan karena pria cenderung mempunyai berbagai faktor yang dapat memicu terjadinya hematemesis dan atau melena seperti faktor gaya hidup yang dipenuhi oleh kesibukan dan stres, pola makan yang tidak sehat, konsumsi rokok, serta alkohol. ${ }^{15}$

Kasus gastritis erosif didapatkan terbanyak pada kelompok umur 61-70 tahun sebanyak 4 kasus (26,6\%). Hasil ini sesuai dengan penelitian Akil pada tahun 2009, kasus terbanyak ulkus duodenum pada kelompok umur 45-65 tahun. ${ }^{11}$

Tingginya kasus hematemesis dan atau melena pada kelompok umur lebih dari 50 tahun pada penelitian ini mungkin disebabkan karena pada kelompok umur tersebut cenderung mengonsumsi OAINS jangka panjang karena penyakit degeneratif yang diderita. OAINS memiliki efek toksik langsung ke 
mukosa gaster, meningkatkan produksi asam lambung, serta menghambat pembentukan prostaglandin sehingga dapat menimbulkan erosi pada gaster. ${ }^{16}$ Atrofi pada mukosa, kelenjar, dan otot-otot pencernaan akibat penuaan pada kelompok umur tersebut dapat memudahkan terjadinya erosi mukosa saluran pencernaan sehingga dapat menimbulkan perdarahan saluran cerna. ${ }^{17}$

Distribusi frekuensi lokasi lesi pada pasien hematemesis dan atau melena, terlihat bahwa lokasi lesi paling banyak yang ditemukan adalah gaster sebanyak 79 kasus (48,8\%), kemudian diikuti dengan esofagogaster sebanyak 35 kasus $(21,6 \%)$, dan esofagus 25 kasus (15,4\%). Hasil yang berbeda ditemukan pada penelitian Alema et al pada tahun 2012 di RS Lacor Uganda, dimana lokasi lesi terbanyak dari 224 pasien adalah pada esofagus 127 kasus $(56,7 \%)$ dan gaster 38 kasus (17\%). ${ }^{14}$

Pada penelitian ini, gaster merupakan lokasi lesi yang paling banyak dikenai. Hal ini kemungkinan disebabkan karena gaster merupakan organ yang paling sering dan lama berkontak dengan berbagai makanan atau minuman yang menyebabkan iritasi. Misalnya makanan yang terlalu pedas, minum kopi atau alkohol, serta berbagai obat-obatan yang dapat mengiritasi lambung. ${ }^{15}$

\section{KESIMPULAN}

Kasus terbanyak yang ditemukan pada pasien hematemesis dan atau melena adalah ulkus gaster yaitu $27,8 \%$. Berdasarkan jenis kelamin, pria lebih banyak didapatkan dibanding wanita yaitu pria $64,8 \%$ dan wanita $35,2 \%$ dengan rasio $1,8: 1$. Kelompok umur terbanyak adalah pada kelompok umur 51-60 tahun yaitu sebanyak 29,0\%. Lokasi lesi yang paling banyak ditemukan adalah gaster sebanyak $48,8 \%$.

\section{DAFTAR PUSTAKA}

1. Djojoningrat D. Perdarahan saluran cerna bagian atas (hematemesis melena). Dalam: Buku Ajar Gastroenterologi. Edisi ke-1. Jakarta: Interna Publishing; 2011.hlm.33-43.

2. Abdullah M. Perdarahan saluran cerna bagian bawah (hematokezia) dan perdarahan samar (occult). Dalam: Buku Ajar IImu Penyakit Dalam, Edisi Ke-5. Jakarta: Interna Publishing; 2009. hlm. 453-9.
3. Saltzman J. Acute upper gastrointestinal bleeding. Dalam: Current Medical Diagnosis and Treatment. Edisi ke-52. New York: McGrawHill; 2009. hlm.32442.

4. Simadibrata M. Pemeriksaan endoskopi saluran cerna. Dalam: Buku Ajar IImu Penyakit Dalam. Edisi ke-5. Jakarta: Interna Publishing; 2009. hIm. 467-73

5. Kolopaking MS. Pemeriksaan endoskopi saluran cerna. Dalam: Buku Ajar IImu Penyakit Dalam. Edisi ke-3. Jakarta: Balai Penerbit FKUI; 2001. hlm.239-45.

6. McQuaid K. Gastrointestinal bleeding. Dalam: Current Medical Diagnosis and Treatment. Edisi ke- 52, New York: McGrawHill; 2010.hlm.580-3.

7. Hreinsson JP, Kalaitzakis E, Gudmunsson S, Bjornsson ES. Upper gastrointestinal bleeding: incidence, etiology, and outcomes in a population based-setting. Scandinavia Journal of Gastroenterology. 2013;48:439-47.

8. Hearnshaw SA, Logan RFA, Lowe DD, Travis SPL, Murphy MF, Palmer KR. Use of endoscopy for management of acute upper gastrointestinal bleeding in UK: results of a nationwide audit. Gut. 2010;10:1136.

9. Adi P. Pengelolaan perdarahan saluran cerna bagian atas. Dalam: Buku Ajar IImu Penyakit Dalam. Edisi ke-5. Jakarta: Interna Publishing; 2009.hlm.447-52.

10.Sanusi I. Tukak lambung. Dalam: Buku Ajar Gastroenterologi. Edisi ke-1. Jakarta: Interna Publishing; 2011.hlm.327-36.

11. Akil H. Tukak duodenum. Dalam: Buku Ajar Ilmu Penyakit Dalam. Edisi ke-5, Jakarta: Interna Publishing; 2009.hlm.523.

12. Julius. Tumor gaster. Dalam: Buku Ajar IImu Penyakit Dalam. Edisi ke-5. Jakarta: Interna Publishing; 2009.hlm.576-80.

13. Syam AF. Tatalaksana perdarahan saluran cerna atas. Dalam: Symposium on Gastrointestinal Endoscopy and Digestive Disease. Edisi ke-1. Jakarta: Interna Publishing; 2011.hlm.46-53.

14. Alema ON, Martin DO, Okello TR. Endoscopic findings in upper gastrointestinal bleeding patients at Lacor Hospital. Northern Uganda. African Health Sciences. 2012;4:518-21. 
15. Hadi S. Tatalaksana perdarahan saluran cerna bagian atas. Dalam: Buku Ajar Gastroenterologi. Edisi ke-1. Jakarta; Interna Publishing; 2002. hlm. 22-4, 84-145, 146-247, 315-21, 614.

16. Pratomo W. Gastritis dan gastropati. Dalam: Buku
Ajar Gastroenterologi. Edisi ke-1 Jakarta: Interna Publishing; 2011.hlm.320.

17. Utama H. Aspek fisiologik dan patologik akibat proses menua. Dalam: Buku Ajar Geriatri. Edisi ke4. Jakarta: Balai Penerbit FKUI; 2004.hlm.58. 